\title{
Content and access provision in a discrete competition model
}

\author{
Petrus H Potgieter*
}

Bronwyn E Howell ${ }^{\dagger}$

Received: 27 July 2021; Revised: 18 September 2021; Accepted: 17 November 2021

\begin{abstract}
The non-rival, non-excludable and infinitely expansible characteristics of digital goods with marginal cost of zero strongly favours the use of bundling strategies. Theoretical tractability requires most models in the current literature to make highly stylised assumptions, rarely observed or anticipated in the real-life situations, motivating inquiry. This paper considers a competition model in which:

- the firms, consumers and differentiated products are finite in number;

- prices are discrete and not continuous;

- consumers may purchase multiple items in a single product category where the degree of complementarity or substitutability of the product categories can also vary across consumers;

- and where consumer-specific cost savings are obtained when purchasing multiple items from the same firm.

Approximate solutions are obtained through numerical simulation. Firms act in concert to maximise the total firm revenue. Our main finding is that the interplay between maximal firm revenue, consumer surplus and prices is very complex and that high firm revenue and high consumer surplus are not antithetic. It suggests also that consumer surplus and market concentration are not necessarily related. Many market outcomes that are observed may be due to chance rather than design as diverse outcomes can accompany situations that are, to the firms, difficult to distinguish.
\end{abstract}

\footnotetext{
${ }^{*}$ Department of Decision Sciences, University of South Africa, Pretoria, South Africa, email: potgiph@unisa.ac.za

${ }^{\dagger}$ School of Management, Victoria University of Wellington, Wellington, New Zealand, email: bronwyn.howell@vuw.ac.nz
} 


\section{Graphical abstract}

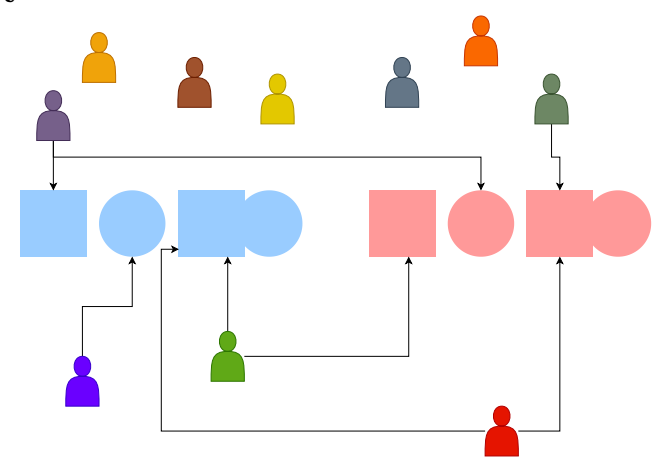

Key words: Bundling; OR in marketing; OR in telecommunications; pricing; simulation.

\section{Highlights}

- Discrete model with finite number of firms, consumers and differentiated digital products.

- Consumers value firm-specific versions of products differently.

- Mixed bundling with discounted bundles available as well as individual products.

- Discrete prices set by firms who collude to maximise joint revenue.

- Multiple or zero purchases by consumers.

- Simulations show diverse market outcomes due to chance as firms have imperfect information.

\section{Introduction}

Bundling is a key feature in the markets where information goods are exchanged. Information goods include music and other audio streaming, gaming and subscription television or video streaming services that make up a substantial share of the modern economy. They are characterised by being non-rival, non-excludable, infinitely expansible and having near-zero marginal cost; see [30]. Consumption of these services takes up an ever-larger share of many consumers' leisure time. Firms are faced with the challenge of how to price their offerings of information goods, since a cost-plus model is no longer appropriate; see [8], [10] and [17].

Bundling is an important and useful sales strategy that holds benefits for firms as well as consumers. Information goods with demand independent of other products (which may or may not be information goods) will yield higher profits when bundled with that other product and when the package is sold at a single price; see [6], [28] and [24]). Under a surprisingly large number of circumstances, profits will still be maximised from bundle sales even when demand for the products is not independent (see [13] and [15]) and under some circumstances when the zero marginal cost assumption is relaxed; see [5]. The challenge for firms is to price the components and the bundle so as to maximise profits, yet these prices frequently yield higher consumer welfare than the sale of (only) separate 
components. The challenge for policy-makers, competition authorities and regulators is to ascertain circumstances where bundling harms welfare, and thereby when (and how) to intervene.

Consider, for example, a market in which a single firm produces two products and in which there are two consumers (A and B) with the following willingness-to-pay (WTP) for the two products; see Table 1.

\begin{tabular}{lcc}
\hline \hline & $\mathrm{A}$ & $\mathrm{B}$ \\
\hline Product 1 & 10 & 3 \\
Product 2 & 4 & 10 \\
\hline
\end{tabular}

Table 1: A basic example where bundling increases welfare.

The firm acts to maximise revenue and if the products are sold separately (that is, in an unbundled scenario), the firm would charge $\$ 10$ for product 1 and the same for product 2 in order to realise revenue of $\$ 20$. Consumer A purchases product 1 and consumer B purchases product 2 and nothing else. We assume the marginal cost of production to be zero.

The firm could see an opportunity to stop selling the products separately and offer only a bundle consisting of both products for which it charges $\$ 13$. In this case (WTP being considered additive), both consumers will purchase the bundle at the price of $\$ 13$ and not only would the consumers find more of their demand satisfied (at a higher consumer surplus) but the firm would also find its revenue increased to $\$ 26$.

Both consumers pay a modest amount more than they would have expended in the unbundled case and now receive both products. In fact, the total welfare in the unbundled case is $(20=0+0+20)$ and in the bundling case it is $(27=1+0+26)$, being the sum of each individual consumer's surplus amounts and the firm's marginal profit respectively.

The digital economy commonly sees providers offering products and services to consumers in bundles. Firms, policy-makers, competition authorities and courts are challenged to consider the actual and possible effects of bundling on profits, consumers and total welfare. Different ways of evaluating these complex cases are required and numerical analysis of the output of simulation models endeavouring to capture the specific characteristics of the real-life cases offers an alternative means of evaluation.

\section{$2 \quad$ Background}

In practice, many different forms of bundling have emerged, with different strategic motivations and different effects on both the quantum and distribution of static and dynamic welfare.

Pure bundling, or tying, occurs where products can only be obtained together, in the bundle. Examples include multiple stories and advertisements printed in a newspaper edition (or distributed via a website), programming bundled into a television channel and unlimited usage broadband plans (effectively access and usage components bundled together for a single price). A variant of pure bundling occurs when purchase of a second 
product is contingent upon purchase of a first (e.g. upgrades to software packages, premium paid television content and the upgrade of a 'regular' size purchase to 'super').

Mixed bundling occurs when customers face no impediments to maximising their surplus by buying a product on its own or in a bundle, either offered by a single firm or constructed from the component offerings of a variety of competing firms. An example is telecommunications triple and quadruple play packages of television, Internet and telephony (fixed and mobile) products, where consumers can choose either the bundle or any of the components. A further variant is bundle-size pricing where consumers can purchase any $m$ of $n$ products ( $m$ less than $n$ ) for a single price. Examples include " 3 for the price of 2 " clothing offers, attendance at any $m$ events in an $n$-event subscription series (e.g. theatre, concert or football season) and access to a specific number of designated attractions in a theme park or tourist destination within a given time period. Multi-trip tickets on public transport can also be considered a form of bundle-size pricing.

\subsection{Theoretical models}

The theoretical literature on bundling, dating from the seminal paper [31], is populated by many different models addressing the effects of different forms of bundling on profits, consumer welfare and overall market efficiency, in many different market contexts. For example, [1], [29], [18] and [34] consider pure bundling, [1], [25] and [13] study mixed bundling and [15] bundle size pricing. Many models consider the questions from the perspective of a monopoly provider selecting component and bundle prices to maximise extraction of consumer surplus. Others focus on duopoly, with the specific anti-trust concerns that bundling can be used to foreclose competitors providing one (see [32]) or more (see [14] and [27]) of the bundle components, or that bundling can be used to create vertical product differentiation and thereby relax price competition (see [9], [12] and [19]). Bundle-against-bundle competition tends to be fiercer than competition in separate sales; see [5] and [4]. More recent models consider an oligopoly context; see [34].

While much separates the models, common to all is that bundling strategy outcomes depend crucially upon the distributions of consumers' willingness-to-pay (WTP) for the bundle components, both separately and in combination with each other. In the case of competition (anti-trust), the extent to which the competing products in each category, and hence the consequent bundles, are considered by consumers to be homogeneous substitutes or differentiated variants, is material. Their relevance in specific circumstances therefore depends crucially upon differences in demand-side characteristics as much as upon firms' strategic intent and/or market structure. However, the inherent complexity that characterises the markets in which product bundles (and information product bundles in particular) are offered poses significant challenges to theoretical modelling. Of necessity, simplifications must be made.

[26] investigates the bundling of retail products with non-zero marginal cost of production where firms may decide to offer a pure bundle or unbundled products (not mixed bundling, where both the individual products and the bundle may be purchased) and show in an analytical context that the optimal decision of the firm depends on the correlation of the demand for the products. A computational approach is used by [20] which also considers the correlation of demand for two non-information retail products where a retailer wishes 
to clear the inventory of one of the products. A mixed bundling approach is studied by [33] for telecommunications services, under the assumption that these are information goods and considering the cases of available demand data as well as that of incomplete information and comparing the model results to bundle prices observed in the market.

For tractability, most models adopt a two-dimensional Hotelling framework to capture product differentiation, with consumers uniformly distributed on the square ([2], [15], [13] and [34] are notable exceptions). This necessarily limits consideration to scenarios with two firms and two products, with preferences distributed independently and uniformly in each dimension. Further assumptions to increase tractability include full market coverage (prices are set so that all consumers buy something) and symmetric valuations of the goods and bundles. Furthermore, distributions are considered to be continuous, in order to create the differentiable demand functions required for analysis. Whilst some notable endeavours have been made to formulate general theories of commodity bundling, where at least one of these constraints has been relaxed (e.g. [3] relaxes the assumption that a consumer's valuation for a bundle of products is the sum of the valuations of the products individually). These are generally limited by other constraints imposed by the two-firm, two-product Hotelling model formulation, e.g. complete coverage and symmetric products.

\subsection{Practical limitations}

It begs the question, therefore, how much weight is (or can be) given to these models by firms actually making decisions about setting their bundling strategies and prices. While theoretically firms may be able to choose prices to achieve specific objectives, (e.g. foreclosure of rivals) can they actually achieve this in practice, via the pathways indicated in the models? And can regulators and competition authorities presume that prices and outcomes observed ex post are in fact more probably the result of explicit strategies determined scientifically using the models, or the products of chance that the actual consumer WTPs and other preference characteristics (e.g. product substitutability and complementarity, demand correlation) just so happen to follow the patterns assumed in the models?

[11] uses a mixed integer non-linear program to investigate the bundling and pricing decisions of a single firm in the presence of competitors who do not react to its decisions and based on utility maximisation by customers. They highlight the immense combinatorial complexity of the bundling decision (for example, for a firm providing a large number of video entertainment channels) and use a weighted sum of the consumers' reserve prices for the individual items as the WTP for a bundle. This work uses a somewhat similar approach, taking into account however, product differentiation and the possibility that consumers might purchase bundles or products from different firms.

[21] questions the relevance of applying [32] and [14] supporting a strategy of strategic foreclosure to analyse a merger proposed in 2017 between a pay television and a broadband provider because the circumstances prevailing violated the assumptions of perfect complementarity, duopoly, linear demand, symmetrical substitutability, and complete coverage assumptions upon which the outcomes of the models crucially depend. [22] and [23] developed a simulation and numerical analysis model calibrated to the relevant market 
circumstances to explore outcomes when a number of these assumptions were relaxed and illustrate how it could have assisted the competition authority in making its decision.

This paper begins to address the question of how useful these models are in addressing the dilemmas firms face in choosing their bundling and pricing strategies, and whether the simulation and numerical analysis approach adopted in our prior papers can likewise offer different insights, for both the firms seeking to maximise (or at least increase) profits and regulators assessing the effects of bundling on consumer and total welfare. The inquiry is motivated in part by [15], who observed that despite the theoretical potential for firms to use capacious computing resources to compute optimal prices for all components and bundles in mixed bundling scenarios, this strategy is rarely observed in practice. Whilst acknowledging that computational limitations preclude this approach for scenarios of more than a few products, they postulated instead that different bundling strategies - notably bundle-sized pricing - deliver approximately similar profits but for much less effort.

Intuitively, it might appear that models optimising prices using a discount based on the sum of components (see [19], [3] and [34]) might prove more practical, but they too pose computational challenges as the number of products in the bundle(s) grows large. Furthermore, apart from [34], they are constrained by their duopoly limitations. This led us to consider other cost and effort-reducing strategies adopted by firms when pricing and offering product bundles, the extent to which the theoretical models capture these practical realities, and the potential to utilise simulation and numerical analysis as an alternative means of understanding the effects of different pricing and bundling strategies on market outcomes.

Perhaps unsurprisingly, it appears (from informal interviews with stakeholders in the United States, Europe, New Zealand and South Africa) that firms in the telecommunications and media sector rarely price their bundles (at least for the purposes of posted prices) by using the profit-maximising approach of the models. The simple reason for this is the lack of detailed consumer WTP information for the entire market. Although it is noted that individual offers appear to be made frequently to specific existing customers, based upon records of individual purchase history, largely to prevent defection to rival providers. At best, they may have a general idea of the distribution of consumers' WTP for individual products and their joint distribution if offered in bundles, but these are subject to considerable levels of uncertainty.

When discounts are offered for new bundles of existing products, these tend to be in the form of either specific dollar or percentage discounts on the posted prices for the components, based upon proprietary knowledge (estimates) of what the market might bear and how competitors might respond. Rarely are these discounts scientifically determined in the manner of models. In the case of new products, these may be offered initially in bundles with existing products, e.g. as "free with an existing purchase for a limited time," to existing customers, but are usually offered at the same time at a stand-alone price to attract new sales. The bundle price at the end of the promotional period will typically increase to include the discounted stand-alone price. 


\section{$2.3 \quad$ A simulation approach}

Drawing from both the theoretical models (principally [15], [13], [3] and [34]) and observed practice, we have constructed a general model allowing us to use simulation and numerical analysis to explore outcomes and strategies under a variety of assumptions that plausibly reflect the conditions under which firms set their prices and bundling strategies. The characteristics in the current application reflect those in markets for bundling of broadband access and content applications, but the model is general enough to be adapted to analyse bundling in other markets. The firms offer differentiated products priced at discrete price points (not on a theoretical mathematical continuum) and the consumers are a finite set (of individuals and/or groups) selected from any given distribution. The extent of complementarity between the products in the bundle is determined at the level of each consumer, with firm preferences (brand loyalty) and cost savings from buying bundled products from the same firm likewise being specific to each consumer. The parameters for the distributions of each of these characteristics can be varied exogenously, as can the magnitude of the firm-specific discount offered for product bundles. Unlike the theoretical models, no assumptions of symmetry in the demands for products or bundles are necessary.

In this paper, our simulations undertaken using the model under more (we argue) realistic assumptions of actual behaviour than the theoretical models, demonstrate the degree to which outcomes depend, in more than one way, on chance. We also use them to confirm more generally the assertions of [15] that beyond a certain level, the returns to computational effort in pursuit of higher profits are not necessarily large. [7] also points out that approximate prices can be very effective in finding near-optimal profits. This adds a further explanation for the observation that firms tend not to engage in sophisticated processes in setting their bundling prices and strategies. It also further reinforces the cautions to regulators and competition authorities offered in our prior papers about the relevance of the highly-stylised theoretical models when evaluating bundling actual cases. The use of simulation models in addition to other analyses in both firm price-setting and competition law and regulatory analysis is further supported.

\section{Methodology}

In the current model, we consider two firms, both of which sell two products, one of which is valued more highly by consumers than the other. This assumption differs from models presuming symmetrical distribution of consumers' product valuations (e.g. [14] and [32]). We also assume the firms can bundle arbitrarily and that the consumers' WTP is known to the firms who then collude in making pricing decisions so as to maximise their revenue. This amounts to the firms maximising joint profit, given the near-zero marginal cost of the information goods. Whilst it is true that firms will not know the precise WTPs of all consumers in reality, we contend that the usefulness of our model comes from firms' (or regulators' or competition authorities') shared assumptions about the distributions of the relevant factors, which would be necessary for drawing inferences from any of the other theoretical models as well. 


\subsection{Model description}

The model incorporates a principle of bounded rationality and constrained resources by limiting the ability of the firms to determine exactly their revenue-maximising pricing strategies. This is captured in two ways. First, we presume firms set bundle discounts on the basis of discounting the sum of the stand-alone prices rather than evaluating all possible combinations of component and bundle prices. Second, we structure the simulation process to allow different levels of effort to be exerted in the search for a revenue-maximising strategy by varying a parameter of the model that determines how many options a firm may examine.

The distribution of consumer information across the firms and the strategies available to them are assumed to be symmetrical. Each firm knows the consumers' preferences (essentially shares the same assumptions about the distributions of the relevant WTP factors, so could generate a similar set of customers and analyse the scenarios accordingly) and has equivalent access to the model and computational resources. This allows us to assume that each firm will be able to anticipate the other's optimal price choice sets, and therefore allows the firms to collude in setting prices. That is, without explicit discussion, each presumes the other can, and indeed has an incentive to, search for the prices offering the joint best outcome. This is plausible if, for example, each was using the same consumer WTP assumptions when pricing its entry into a new product category where each knows its rival(s) will simultaneously introduce a similar (differentiated) product variant. This model differs from [23] and [22], which considered monopoly pricing by a firm with market power seeking to foreclose its rivals. Like those models, the one in this paper incorporates the behaviours most-feared by regulators and competition authorities because of potential harms to competition, total and consumer welfare.

Our simulations consist of rounds that involve generating a scenario of random consumer willingness-to-pay (WTP) values, then determining profit-maximising prices in each round for the two firms under the assumption that consumers make decisions that maximise their surplus. In each round, the firms are allowed to examine a fixed number (iterations) of randomly sampled prices and determine what their revenue would have been, had prices been set like that. Generally, the higher the number of iterations allowed, the better the firms will be at maximising their revenue.

Consumers may purchase any combination of products or bundles, with no restriction placed on purchasing two (differentiated) variants of the same product if the marginal benefit from buying the second exceeds the additional price charged. In this regard, our model follows [3], [4] and [34]. We assume that the individual products (two per firm) have integer prices. Bundle prices are expressed as discounts on the sum of the component prices (as per [3]). In this model, firms determine the price of a bundle by giving a compounded discount of $10 \%$ for each item in the bundle. The two-item bundles under discussion here are therefore priced at $81 \%$ of the sum of the prices of the products in the bundles since $0.81=0.9 \times 0.9$. This pricing strategy appears to be a realistic aspect of the model. Integer component prices (as proxies for the frequently-observed \$xx.99) offer the additional advantage of side-stepping the Bertrand paradox (where two firms in competition sell exactly at marginal cost and hence there is zero profit and, furthermore, entry of new firms does not affect the price). 
Our model helps both firms and regulators to understand the complexity of underlying market forces in very simple scenarios. We do not exaggerate the extent to which our model reflects market reality but propose that the assumption that firms always find optima, very common in the theoretical literature, is far from realistic. A model with integer prices and a finite number of consumers (as a proxy for groups of consumers) offers many insights into actual bundling scenarios.

\subsection{Details of the model}

In the present model, consumers' willingness to pay (WTP) are built up from the following uniformly distributed.

- A basic WTP $w_{j}^{i}$ for each item $j$ for each consumer $i$ (upper bound 7 for the item $j=1$ and 15 for the other $j=2$, ensuring asymmetry in item valuations).

- For each consumer $i$ and each firm $k$ and each item $j$, a premium $p_{j, k}^{i}$ for that firm's item (upper bound 7), reflecting the extent of differentiation between the firms' products. When buying a second item $j$ from another firm, the consumer's welfare increases only by the addition of the firm premium $p_{j, k}^{i}$, thereby accounting for the lower marginal utility from second item purchases not easily addressed in models assuming strictly additive item utilities; see [4].

- For each consumer $i$, a complementarity premium $c^{i}$ for the two items (upper bound 2).

- For each consumer $i$, a firm complementarity premium $f_{k}^{i}$ to reflect the consumer's possible preference for buying both items from the same firm (upper bound 2). This reflects both consumer brand preferences and savings obtained from buying both products from the same firm; see [4].

All upper bounds are strict and all four quantities above are at least (but possibly equal to) zero. Both the firm and complementarity premia for each product pair vary between consumers, differentiating our model from those where the same premia apply to all consumers, firms and product pairs equally. While for the purposes of this paper these premia are independently and uniformly distributed across consumers, the structure of the model allows for the use of different distributions, and correlations between any or all of the factors, in future analyses.

The basic product set of firm $k$ is

$$
B_{k}=\{(k, 1),(k, 2)\},
$$

where the first coordinate denotes the firm and the second the type of product. In what follows, we often write $\{12\}$ instead of $(1,2)$ to denote the second product of the first firm etc. The combined offering of firm $k$ is

$$
B_{k}=\{\{(k, 1)\},\{(k, 2)\},\{(k, 1),(k, 2)\}\},
$$

which is a set the elements of which are three subsets representing the three offerings product 1 on its own, product 2 on its own or the bundle consisting of both products. 
Consumers choose from all possible subsets (including the empty set) of $B_{1} \cup B_{2}$ so the choice set is

$$
C=\left\{z \mid z \subseteq B_{1} \cup B_{2}\right\}
$$

For an option $z \in C$ the valuation of consumer $i$ is

$$
V^{i}(z)=\sum_{\substack{j \\(k, j) \in x^{\prime}}} w_{j}^{i}+\sum_{\substack{j, k \\(k, j) \in x^{\prime}}} p_{j, k}^{i}+\sum_{\substack{k \\(k, 1) \in x^{\prime},(k, 2) \in y^{\prime}}} c^{i}+\sum_{\substack{k \\\{(k, 1),(k, 2)\} \in z}} f_{k}^{i}
$$

with $x^{\prime}=x \otimes z$ and $y^{\prime}=y \otimes z$, which incorporates all of the above. Prices for the products and bundles are determined as follows. The firms determine a basic price set $\pi$ from

$$
\Pi=\left\{g \mid g: B_{1} \cup B_{2} \mapsto \mathbb{N}\right\},
$$

where $\mathbb{N}$ denotes the set of natural numbers, that is they assign an integer price to each basic product. For each $\pi \in \Pi$ we extend the price to the choice set $C$ by defining

$$
\pi^{\prime}(z)=\sum_{x \in z} 0.81^{\max \{0,|x|-1\}} \sum_{y \in x} \pi(y)
$$

that is, the price of a single item is as defined by $\pi$ and the price of a bundle of two is $81 \%$ of the sum of the prices of the individual components - as described above. For a given $\pi$ each customer has maximal consumer surplus

$$
S_{\pi}^{i}=\max _{z \in C} V^{i}(z)-\pi^{\prime}(z)
$$

which is always at least zero and optimal choice set

$$
P_{\pi}^{i}=\left\{z \in C \mid V^{i}(z)-\pi^{\prime}(z)=S_{\pi}^{i}\right\}
$$

which may contain (only) the empty set and might contain several options that are both maximal for the given customer. For a given $\pi$ then the firms' joint revenue is

$$
R_{\pi}=\sum_{i} \frac{1}{\left|P_{\pi}^{i}\right|} \sum_{z \in P_{\pi}^{i}} \pi^{\prime}(z)
$$

where the fraction is for averaging over consumers' possible equivalent choices. The firms approximate a solution to the problem

$$
\max _{\pi} R_{\pi}
$$

by randomly picking $\pi$ from the search space for a specified number of iterations and selecting the optimum among the options examined. In any round the customers' WTP parameters are selected randomly, subject to the constraints above. The model was constructed with the express goal of incorporating as many realistic aspects of consumer behaviour (as well as a 'worst case' assumption about the firm) rather than for mathematical tractability in the interest of verisimilitude. 


\section{Scenario parameters}

For this paper, we consider a scenario with a single set of WTP values for 100 consumers. This was the first set that we generated after finalising the software for the calculations. There are no grounds for contending that the behaviour observed for the WTP configurations is typical but, equally, there is also no reason to suppose the opposite. We have found it illuminating to consider our model's results in detail for this specific setup.

The numbers were generated according to the model description outlined above, in the programming language Python, using the random number generator of the SystemRandom class which uses operating system sources of (pseudo-)randomness. This is the recommend method of generating good quality random numbers in Python. The summary characteristics of our 100 consumers' WTP values for the basic products follow; see Table 2. $\sigma$ is used to denote the observed standard deviation in the tables throughout.

\begin{tabular}{lrrrr}
\hline \hline Valuation $V^{i}$ & minimum & maximum & mean & $\sigma$ \\
\hline$\{11\}$ & 0.548 & 13.263 & 6.880 & 2.826 \\
$\{12\}$ & 1.475 & 21.734 & 11.298 & 4.714 \\
$\{21\}$ & 0.980 & 13.522 & 7.121 & 2.966 \\
$\{22\}$ & 3.024 & 21.262 & 11.484 & 4.285 \\
\hline
\end{tabular}

Table 2: Consumers' valuation summary for products of firm 1 and firm 2.

The basic product WTP values are as expected and in this instance, the products of firm 2 happen to be valued very slightly higher than those of firm 1. Since each consumer's WTP valuation is composed of a basic valuation and a firm premium (for individual products as well as bundles) and incorporates specific complementarities for the two items and for purchasing from a single firm, we list summary properties of these sets of random numbers as well; see Table 3 .

\begin{tabular}{lrrrr}
\hline \hline Valuation $V^{i}$ & minimum & maximum & mean & $\sigma$ \\
\hline 1 & 0.259 & 6.914 & 3.490 & 1.915 \\
2 & 0.307 & 14.955 & 7.822 & 4.144 \\
\hline
\end{tabular}

Table 3: Consumer basic valuations for item 1 (product $\{11\}$ or $\{21\}$ ) and item $2(\{12\}$ or $\{22\}$ ).

The basic values are augmented by a smaller consumer preference for the version of each item offered by the separate firms. In this study, the distribution of this premium is identical for all of the products and firms. Table 4 shows observed summary statistics.

\begin{tabular}{lrrrr}
\hline \hline Firm premium $p_{j, k}^{i}$ & minimum & maximum & mean & $\sigma$ \\
\hline$\{11\}$ & 0.008 & 6.908 & 3.390 & 1.963 \\
$\{12\}$ & 0.020 & 7.000 & 3.661 & 1.987 \\
$\{21\}$ & 0.008 & 6.908 & 3.390 & 1.963 \\
$\{22\}$ & 0.020 & 7.000 & 3.661 & 1.987 \\
\hline
\end{tabular}

Table 4: Consumer firm-specific premiums for the basic products, as offered by the two firms.

We assume a small positive item complementarity for all consumers. At present, we do 
not suspect that this plays an essential role in the results observed but we have used it in order to employ the model in a maximally flexible form. The details of observed consumer and firm complementarities are provided in Table 5.

\begin{tabular}{rrrrr}
\hline \hline Item complementarity $c^{i}$ & minimum & maximum & mean & $\sigma$ \\
\hline & 0.007 & 1.998 & 1.004 & 0.587 \\
\hline
\end{tabular}

Table 5: Consumer item complementarities.

Consumers are further allowed to have a mild preference for purchasing both items (if, indeed, they do purchase both) from the same firm and this preference need not be firm-neutral.

\begin{tabular}{lrrrr}
\hline \hline Firm complementarity $f_{k}^{i}$ & minimum & maximum & mean & $\sigma$ \\
\hline 1 & 0.013 & 1.976 & 1.092 & 0.575 \\
2 & 0.007 & 1.876 & 1.016 & 0.549 \\
\hline
\end{tabular}

Table 6: Consumer firm complementarities.

In our model, consumers are allowed to purchase an item more than once, i.e., one consumer may purchase $\{11\}$ from firm 1 as well as the bundle from firm 2 or $\{11\}$ as well as $\{21\}$ for example. This is an aspect of our model that mirrors consumers' behaviour with respect to information goods although this behaviour is not very extensive in the example studied here, because the marginal value gained form the second item is generally quite high compared to the first (that is, most consumers consider the firms' variants of each item to be substitutes for each other). However, we intend to evaluate future scenarios where larger variations can occur.

\section{Simulation results}

We allowed the firms respectively 1 000, 10 000, 100000 or 1000000 iterations of optimising their prices in each round so as to maximise the joint profit. Because of the computing requirements, with 1000000 iterations, we could compute 10 rounds only in the time available. For the other iteration limits, we were able to calculate 100 rounds of each. That is, we have 100 distinct instances of the firms getting 100000 chances of examining the results of setting prices a certain way and choosing the optimal observed pricing strategy.

Obviously, the results tend to get better from the point of view of the firms' joint revenue as the number of iterations is allowed increases. Nevertheless, a rich variety of outcomes can be observed in all cases, even with 1000000 iterations. From the firms' point of view, a higher number of iterations does not necessarily lead to a better outcome since it is possible, even with a large number of iterations, to miss pricing options that result in high joint revenues. Equally, the optimal price combination could be generated randomly during a 1000 iteration run. 


\subsection{0 iterations}

In our setup, 1000 iterations are rather few and in this instance we also see the greatest divergence of outcomes. It is not unexpected that the consumer surplus reaches a quite high value in one of these rounds since the firms are expending relatively little effort on maximising their total revenue. Consumer surplus is shown in Table 7.

\begin{tabular}{rrrrr}
\hline \hline Consumer surplus & minimum & maximum & mean & $\sigma$ \\
\hline & 335.970 & 821.530 & 552.877 & 121.292 \\
\hline
\end{tabular}

Table 7: Consumer surplus range for 100 rounds of 1000 iterations.

Nevertheless, although the individual firms' profits (i.e. revenue since we assume the marginal cost of the products to be zero) vary widely, the total profit is subject to relatively modest variation - even with so few iterations. This suggests that firms might trade effort in maximising their own profit for effort to share their joint revenue. In our simulations in this paper, for example, the increase in joint revenue from the increased effort through employing a larger number of iterations has the effect of increasing the mean joint profit by only about 5\%. A larger number of iterations has in this work however reduced the variation in the individual firm's revenue. The profits of the individual firms are shown in Table 8 .

\begin{tabular}{lrrrr}
\hline \hline Profit & minimum & maximum & mean & $\sigma$ \\
\hline 1 & 0 & 1128.800 & 612.291 & 189.590 \\
2 & 243.000 & 1301.980 & 775.070 & 187.486 \\
total & 1301.980 & 1454.710 & 1387.361 & 27.157 \\
\hline
\end{tabular}

Table 8: Profit range for 100 rounds of 1000 iterations.

Prices charged by the firms in these rounds have a large range and include cases where one of the firms prices itself out of the market. Despite the underlying consumer valuations of the individual items being identical, the individual firm's pricing of the items is starting to exhibit a bifurcation, with firm 1 pricing lower than firm 2 for item 1 and higher for item 2. The sum of the average component prices for each firm, however, is essentially identical (\$21.41 compared to $\$ 21.49)$. This is likely a function of the slightly higher difference observed in the average WTPs of firm 1's components to those of firm 2, given the distribution of firm preference and item complementarity premia across the consumer sample. Table 9 provides more detailed results.

\begin{tabular}{lrrrr}
\hline \hline Prices & minimum & maximum & mean & $\sigma$ \\
\hline$\{11\}$ & 4 & 20 & 8.590 & 2.182 \\
$\{12\}$ & 8 & 18 & 12.900 & 2.124 \\
$\{21\}$ & 5 & 14 & 9.490 & 2.317 \\
$\{22\}$ & 8 & 17 & 11.920 & 1.963 \\
\hline
\end{tabular}

Table 9: Price ranges for 100 rounds of 1000 iterations.

The mean frequency of various purchase decisions is most interesting for 1000 rounds since here we see some multiple purchases of the individual items (e.g. $\{11\}$ as well as 
$\{21\}$ ). As would be expected, this happens only for the first, cheaper (lower-valued) of the two items. Notably, more firm 2 bundles are sold than firm 1 bundles. This reflects the combined effect of the slightly higher consumer valuations for firm 2's variants and the higher prices of the individual components. Cross-firm bundling $(\{\{12\},\{21\}\}$ and $\{\{22\},\{11\}\})$ also occurs; see Table 10.

\begin{tabular}{lr}
\hline \hline Consumer choice & Mean frequency \\
\hline$\{\{11,12\},\{21\}\}$ & 0.430 \\
$\{\{21,22\},\{11\}\}$ & 0.620 \\
$\{\{12\},\{21\}\}$ & 0.725 \\
$\{\{21\}\}$ & 2.155 \\
$\{\{22\},\{11\}\}$ & 2.775 \\
$\{\{12\}\}$ & 2.875 \\
$\{\{22\}\}$ & 2.885 \\
$\{\{11\}\}$ & 5.915 \\
\{\} & 11.780 \\
$\{\{11,12\}\}$ & 29.555 \\
$\{\{21,22\}\}$ & 40.285 \\
\hline
\end{tabular}

Table 10: Consumer choice for 100 rounds of 1000 iterations.

Where consumers have more than one optimal choice, we count each possibility but weight it by the number of equivalent choices for that round. This explains why the table above has the digit 5 in the third decimal place in several lines. On average more than $10 \%$ of consumers purchase nothing at all. Purchasing a bundle from a single firm is the most common behavior, even though single products are available and the bundle discount is relatively modest.

\subsection{0 iterations}

For 10000 iterations, we see the total profit subject to even smaller variation and fewer multi-purchases of items by the consumers. The mean profit increases by around $3 \%$, and consumer surplus decreases by $10 \%$ compared to the 1000 iteration values; see Tables 11 and 12 .

\begin{tabular}{rrrrr}
\hline \hline Consumer surplus & minimum & maximum & mean & $\sigma$ \\
\hline & 353.200 & 696.560 & 495.861 & 88.166 \\
\hline
\end{tabular}

Table 11: Consumer surplus range for 100 rounds of 10000 iterations.

\begin{tabular}{lrrrr}
\hline \hline Profit & minimum & maximum & mean & $\sigma$ \\
\hline 1 & 305.300 & 845.200 & 669.376 & 105.483 \\
2 & 589.860 & 1114.400 & 760.687 & 103.835 \\
total & 1398.680 & 1458.560 & 1430.062 & 12.281 \\
\hline
\end{tabular}

Table 12: Profit range for 100 rounds of 10000 iterations. 
The bifurcation of the average component prices for each item observed in the 1000 iteration case is further emphasised. Firm 1's price for item 1 falls and its price for item 2 rises, whereas for firm 2, it is the item 2 price that falls and the item 1 price that rises. Firm 1's average prices for the two items diverge, whereas firm 2's average prices for the two items converge. That is, firm 1 tends to price the two items close together and firm 2 has one significantly cheaper than the other. Furthermore, a separation in the sums of the average component prices is emerging ( $\$ 21.88$ and $\$ 22.3$ ). This would reflect the greater benefits available to the colluding firms exerting more effort to find prices that more precisely reflect the differences in underlying consumer WTP as can be seen in Table 13.

\begin{tabular}{lrrrr}
\hline \hline Prices & minimum & maximum & mean & $\sigma$ \\
\hline$\{11\}$ & 6 & 12 & 8.290 & 1.243 \\
$\{12\}$ & 9 & 16 & 13.590 & 1.607 \\
$\{21\}$ & 6 & 13 & 10.550 & 1.705 \\
$\{22\}$ & 9 & 15 & 11.750 & 1.602 \\
\hline
\end{tabular}

Table 13: Price ranges for 100 rounds of 10000 iterations.

Despite the higher sum of component prices, firm 2 still sells more bundles on average than firm 1, but the number is smaller than observed for 1000 iterations. Conversely, firm 1 sells more bundles. Cross-firm bundling of the low-priced items from each firm $\{\{22\}$, $\{11\}\}$ increases. The number of consumers making no purchases on average increases slightly, see Table 14 .

\begin{tabular}{lr}
\hline \hline Consumer choice & Mean frequency \\
\hline$\{\{21,22\},\{11\}\}$ & 0.020 \\
$\{\{11,12\},\{21\}\}$ & 0.030 \\
$\{\{12\},\{21\}\}$ & 0.190 \\
$\{\{21\}\}$ & 0.890 \\
$\{\{12\}\}$ & 1.710 \\
$\{\{22\}\}$ & 3.040 \\
$\{\{22\},\{11\}\}$ & 4.495 \\
$\{\{11\}\}$ & 7.030 \\
\{\} & 13.410 \\
$\{\{11,12\}\}$ & 31.630 \\
$\{\{21,22\}\}$ & 37.555 \\
\hline
\end{tabular}

Table 14: Consumer choice for 100 rounds of 10000 iterations.

In 100 rounds, multi-purchasing by a single consumer was rare and observed only 5 times. The purchasing of one item from firm 1 and the other from firm 2 (the choice $\{\{12\}$, $\{21\}\}$ ) is observed only 19 times in all 100 rounds. On average, an appreciable number of consumers purchase item $\{11\}$ on its own but the dominant behavior with close to $70 \%$ frequency is again to purchase a bundle. 


\subsection{0 iterations}

With 100000 iterations, the total firm revenue is almost constant whereas the consumer surplus still varies fairly widely. On average, however, profit has increased by $1.4 \%$ and consumer surplus has fallen by only $1.8 \%$ compared to the 10000 iteration case; see Tables 15 and 16.

\begin{tabular}{rrrrr}
\hline \hline Consumer surplus & minimum & maximum & mean & $\sigma$ \\
\hline 387.870 & 666.770 & 486.944 & 84.164 \\
\hline
\end{tabular}

Table 15: Consumer surplus range for 100 rounds of 100000 iterations.

\begin{tabular}{lrrrr}
\hline \hline Profit & minimum & maximum & mean & $\sigma$ \\
\hline 1 & 538.565 & 788.800 & 689.223 & 79.272 \\
2 & 650.240 & 914.540 & 761.089 & 78.612 \\
total & 1438.200 & 1458.560 & 1450.312 & 4.711 \\
\hline
\end{tabular}

Table 16: Profit range for 100 rounds of 100000 iterations.

Compared to the 10000 iteration case, average prices for firm 1's components have changed little, but the convergence of firm 2's prices for the two basic items has continued. Notably, the sums of the average prices for the components of each firm have diverged, with firm 1's now being appreciably lower than firm 2's (\$21.88 cf $\$ 22.30)$. This could reflect fine trade-offs between the prices for the components and bundles to induce small, profit-enhancing changes in consumer purchases. Table 17 shows the observed price ranges.

\begin{tabular}{lrrrr}
\hline \hline Prices & minimum & maximum & mean & $\sigma$ \\
\hline$\{11\}$ & 7 & 11 & 8.370 & 1.064 \\
$\{12\}$ & 10 & 16 & 13.520 & 1.127 \\
$\{21\}$ & 7 & 13 & 11.070 & 1.259 \\
$\{22\}$ & 9 & 15 & 11.370 & 1.494 \\
\hline
\end{tabular}

Table 17: Price ranges for 100 rounds of 100000 iterations.

Multi-purchasing has disappeared and the frequency of purchasing nothing at all continues to increase. The purchases of product $\{21\}$ are near zero, as the ever-higher price of the component induces more bundle sales or non-purchase amongst marginal consumers. Cross-firm bundle purchases have increased slightly for the low-price items $(\{\{22\},\{11\}\})$.

\subsection{0 iterations}

The 1000000 iterations are sufficiently many to stabilise the firms' decision to two nearly equivalent (from their point of view) options. The maximal joint profit of 1458.560 is associated with the maximal consumer surplus of 575.710 and the slightly lower profit of 1454.710 with the much lower consumer surplus of 388.870. Furthermore, the lower consumer surplus is associated with prices that are generally but not uniformly not much higher than in the high consumer surplus solution. 


\begin{tabular}{lr}
\hline \hline Consumer choice & Mean frequency \\
\hline$\{\{12\},\{21\}\}$ & 0.180 \\
$\{\{21\}\}$ & 0.310 \\
$\{\{12\}\}$ & 1.370 \\
$\{\{22\}\}$ & 3.570 \\
$\{\{22\},\{11\}\}$ & 4.655 \\
$\{\{11\}\}$ & 6.010 \\
$\{\{$ & 13.800 \\
$\{\{11,12\}\}$ & 33.035 \\
$\{\{21,22\}\}$ & 37.070 \\
\hline
\end{tabular}

Table 18: Consumer choice for 100 rounds of 100000 iterations.

\begin{tabular}{lr}
\hline \hline Product & Price \\
\hline$\{11\}$ & 9.00 \\
$\{12\}$ & 14.00 \\
$\{21\}$ & 11.00 \\
$\{22\}$ & 13.00 \\
\hline
\end{tabular}

Table 19: Product prices for 1000000 iterations and low consumer surplus.

In the low consumer surplus outcome, there is over $20 \%$ of no-purchase decisions whereas the high consumer surplus case has much less exclusion. Also (discussed in the next section), the high consumer surplus case is associated with a higher market share going to the dominant firm. Table 18 shows the resulting consumer choices while Tables 19 and 20 show the product prices resulting in low and high consumer surplus respectively. Table 21 shows the observed consumer surplus range and Tables 22 and 23 show the profit and price ranges.

Since 1000000 iterations really results in one of only two outcomes, the means are less meaningful than where there are fewer iterations.

\subsection{Consumer surplus and concentration}

Figures 1 to 4 show the one-firm revenue concentration ration $C_{1}$ (the share of revenue controlled by the largest firm) for our simulation runs. Clearly $C_{1} \geq 0.5$ by design since there are only two firms. The figures show no clear relationship between $C_{1}$ and consumer surplus. For a smaller number of iterations (where firms do not put in a great deal of effort

\begin{tabular}{lr}
\hline \hline Product & Price \\
\hline$\{11\}$ & 8.00 \\
$\{12\}$ & 12.00 \\
$\{21\}$ & 13.00 \\
$\{22\}$ & 9.00 \\
\hline
\end{tabular}

Table 20: Product prices for 1000000 iterations and high consumer surplus. 


\begin{tabular}{rrrrr}
\hline \hline Consumer surplus & minimum & maximum & mean & $\sigma$ \\
\hline & 388.870 & 575.710 & 538.342 & 74.736 \\
\hline
\end{tabular}

Table 21: Consumer surplus range for 10 rounds of 1000000 iterations.

\begin{tabular}{lrrrr}
\hline \hline Consumer surplus & minimum & maximum & mean & $\sigma$ \\
\hline 1 & 748.310 & 779.600 & 773.342 & 12.516 \\
2 & 678.960 & 706.400 & 684.448 & 10.976 \\
total & 1454.710 & 1458.560 & 1457.790 & 1.540 \\
\hline
\end{tabular}

Table 22: Profit range for 10 rounds of 1000000 iterations.

into maximising revenue) we had more data points since we were able to execute more runs, which explains the larger range of $C_{1}$ values observed in Figure 1 when compared to Figure 3 or Figure 4.

Multiple instances of the same value are represented as a a proportionally larger dot in the scatter plot. With a higher iteration number (that is, a more detailed search by the firms), fewer unique distinct outcomes are observed. For one million iterations (Figure 4) only two distinct outcomes were observed with slightly higher concentration and higher consumer surplus being the dominant one.

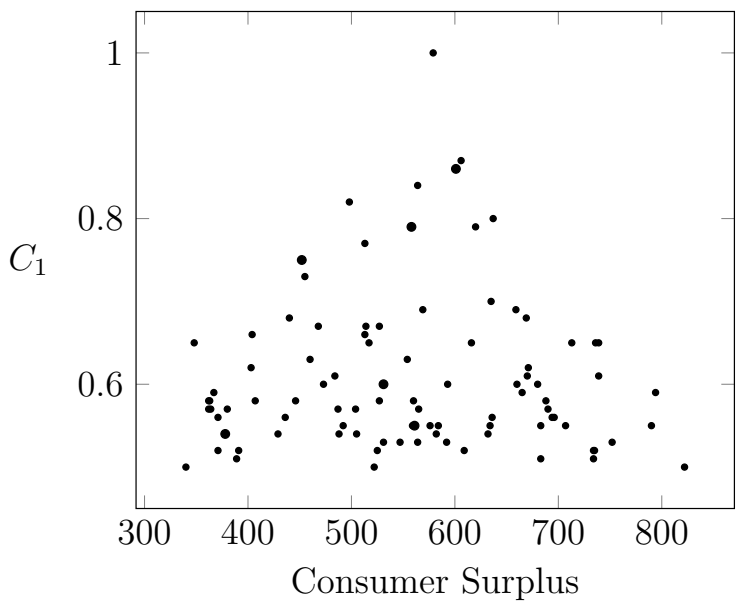

Figure 1: 1000 iterations, $C_{1}$ against consumer surplus.

It is clearly not possible to infer that higher concentration (which arises randomly, in our model) implies lower consumer surplus. Since the firms are colluding on maximising

\begin{tabular}{lrrrr}
\hline \hline Consumer surplus & minimum & maximum & mean & $\sigma$ \\
\hline$\{11\}$ & 8 & 9 & 8.200 & 0.400 \\
$\{12\}$ & 12 & 14 & 12.400 & 0.800 \\
$\{21\}$ & 11 & 13 & 12.600 & 0.800 \\
$\{22\}$ & 9 & 13 & 9.800 & 1.600 \\
\hline
\end{tabular}

Table 23: Price ranges for 10 rounds of 1000000 iterations. 


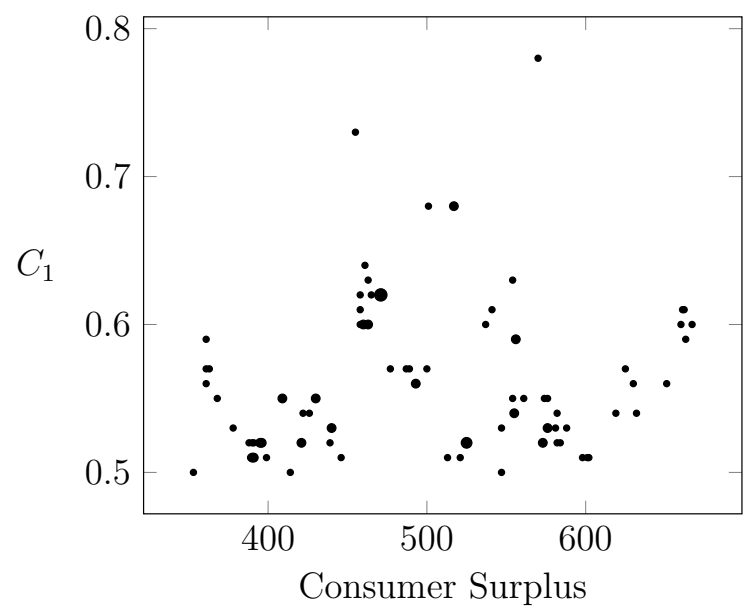

Figure 2: 10000 iterations, $C_{1}$ against consumer surplus.

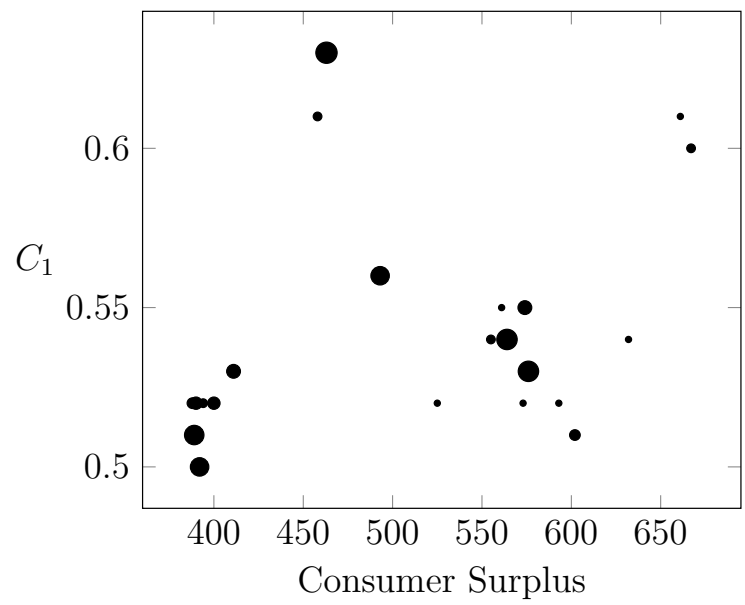

Figure 3: 100000 iterations, $C_{1}$ against consumer surplus.

their joint revenue, this is perhaps not completely counter-intuitive. Nevertheless, even with colluding firms, as in this model, the revenue-maximising strategy is for the firms to share (as with 1000000 iterations) the market nearly equally as they use their ability to offer differentiated products to profit from the consumers' heterogeneous valuations. The nearly equal market sharing appears only when the firms put a great deal of effort (large number of iterations) into finding an optimal strategy.

\section{Conclusion}

[16] and others have pointed out that collusion is not necessarily detrimental to buyers. The work in this paper demonstrates that a wide variety of market outcomes are possible in a bundling scenario where colluding firms have limited ability to search for optimal solutions in what is in fact an intractable combinatorial optimisation problem in the discrete setting which arises in the real world. The single scenario examined here is 


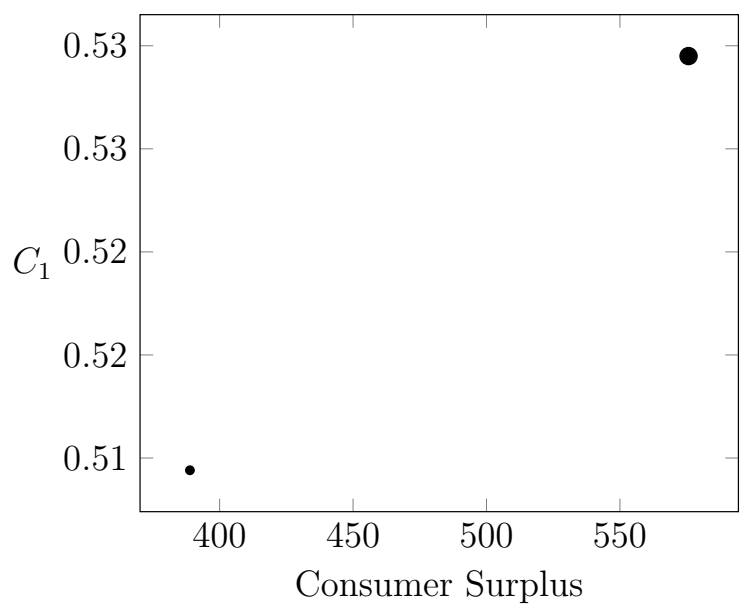

Figure 4: 1000000 iterations, $C_{1}$ against consumer surplus (ten runs having resulted in only two distinct value pairs).

generated from the first set of outputs from a new model calibrated to a number of parameters across dimensions of consumer-specific product valuations and firm preferences. It illustrates that even when firms collude to maximise their joint profits, there are a surprising number of price combinations that yield both high profits and high consumer surplus when bundling is allowed.

Furthermore, it illustrates that few inferences can be drawn from the prices charged for apparently comparable components. For our two firm, two product model, there appears to be little that can be deduced from the relationships between consumer surplus and market concentration (by revenue). Price comparability can also be misleading, as quite small differences in the distribution of consumers' valuations of different dimensions of product differentiation and product complementarity can lead to very different prices for components and bundles, without necessarily harming consumer outcomes.

Firms can and do endeavour to strategically price components and bundles to maximise profits. But given the wide variety of factors that can influence consumers' willingness to pay (WTP), and the computational effort required to determine the optimal prices even when individual consumer WTPs are known, even for a simple two firm, two product case, the application of our model tends to suggest that chance still plays a major role in the outcomes in markets for bundled products. We would also suggest that the process of discovering consumer preferences and the choice of marketing framework (number of basic products, number of bundles) plays a greater role than has been generally appreciated, especially by regulators.

Moreover, the structure of our simulation model appears to confirm that beyond a small amount of initial work, the extra effort exerted in attempting to 'fine tune' bundle and component prices to extract even higher profits may not yield benefits sufficient to cover the additional costs. This may in part explain why firms engaging in bundling do not appear to be using sophisticated models to set their prices. Notwithstanding, we propose to further develop scenarios based upon this model, to determine whether similar results prevail, and further insights are found, as we vary the many parameters in the basic set-up. 


\section{References}

[1] Adams WJ and Yellen JL, 1976, Commodity bundling and the burden of monopoly, The Quarterly Journal of Economics, 90(3), pp. 475-498. https://doi.org/10.2307/1886045

[2] Anderson S AND LuC L, 1993, Why firms may prefer not to price discriminate via mixed bundling, International Journal of Industrial Organization, 11(1), pp. 49-61. https://EconPapers.repec.org/RePEc:eee:indorg:v:11:y:1993:i:1:p:49-61

[3] Armstrong M, 2013, A more general theory of commodity bundling, Journal of Economic Theory, 148, pp. 448-472.

[4] Armstrong M, 2016, Nonlinear pricing, Annual Review of Economics, 8(1), pp. 583-614. https://doi.org/10.1146/annurev-economics-080614-115650

[5] Armstrong M and Vickers J, 2010, Competitive non-linear pricing and bundling, The Review of Economic Studies, 77(1), pp. 30-60. https://doi.org/10.1111/j.1467-937X.2009.00562.x

[6] Bakos Y and Brynjolfsson E, 1999, Bundling information goods : pricing, profits, and efficiency, Management Science, 45(12), pp. 1613-1630. https://doi.org/10.1287/mnsc.45.12.1613.

[7] BANCIU M AND ØDEGAARD F, 2016, Optimal product bundling with dependent valuations: the price of independence, European Journal of Operational Research, 255(2), pp. 481-495. https://doi.org/10.1016/j.ejor.2016.05.022.

[8] Brennan TJ, 2008, Applying 'merger guidelines' market definition to (de)regulatory policy: pros and cons, Telecommunications Policy, 32(6), pp. 388-398. https://doi.org/10.1016/j.telpol.2008.04.003

[9] Carbajo J, De Meza D and Seidmann DJ, 1990, A strategic motivation for commodity bundling, The Journal of Industrial Economics, 38(3), pp. 283-298. https://doi.org/10.2307/2098499

[10] Carlton DW, 2007, Does antitrust need to be modernized? Journal of Economic Perspectives, 21(3), pp. $155-176$.

[11] Cataldo A, AND FerRer JC, 2017, Optimal pricing and composition of multiple bundles: a two-step approach, European Journal of Operational Research, 259(2), pp. 766-777. https://doi.org/10.1016/j.ejor.2016.11.010

[12] Chen Y, 1997, Equilibrium product bundling, The Journal of Business, 70(1), pp. 85-103. http://www.jstor.org/stable/2353482

[13] Chen Y and Riordan MH, 2013, Profitability of product bundling, International Economic Review, 54(1), pp. 35-57. https://doi.org/10.1111/j.1468-2354.2012.00725.x

[14] Chог JP, 2008, Mergers with bundling in complementary markets, The Journal of Industrial Economics, 56(3), pp. 553-577. https://doi.org/10.1111/j.1467-6451.2008.00352.x

[15] Chu CS, Leslie P AND SOREnSen A, 2011, Bundle-size pricing as an approximation to mixed bundling, The American Economic Review, 101(1), pp. 263-303. http://www.jstor.org/stable/41038789

[16] Deltas G, Salvo A and Vasconcelos H, 2012, Consumer-surplus-enhancing collusion and trade, The RAND Journal of Economics, 43(2), pp. 315-328. http://www.jstor.org/stable/41723330

[17] Evans D And Schmalensee R, 2013, The antitrust analysis of multi-sided platform businesses, NBER Working Paper Series. http://search.proquest.com/docview/1687885793/

[18] Fang H and Norman P, 2006, To bundle or not to bundle, The RAND Journal of Economics, 37(4), pp. 946-963. https://doi.org/10.1111/j.1756-2171.2006.tb00065.x 
[19] Gans JS And King SP, 2006, Paying for loyalty: product bundling in oligopoly, The Journal of Industrial Economics, 54(1), pp. 43-62. https://doi.org/10.1111/j.1467-6451.2006.00275.x

[20] GÖKGÜR B AND Karabati S, 2019, Dynamic and targeted bundle pricing of two independently valued products, European Journal of Operational Research, 279(1), pp. 184-198. https://doi.org/10.1016/j.ejor.2019.05.022

[21] Howell BE And Potgieter PH, 2017, Never a sporting chance: broadband and content bundling in the merger of two dominant firms, SSRN Scholarly Paper ID 2965966. Rochester, NY: Social Science Research Network. https://papers.ssrn.com/abstract=2965966

[22] Howell BE And Potgieter PH, 2018, Bundles of trouble: can competition law adapt to digital pricing innovation? Competition and Regulation in Network Industries, 19(1-2), pp. 3-24. https://doi.org/10.1177/1783591718801102

[23] Howell BE And Potgieter PH, 2019, Bagging bundle benefits in broadband and media mergers: lessons from Sky/Vodafone for antitrust analysis, Telecommunications Policy, 43(2), pp. 128-139. https://doi.org/10.1016/j.telpol.2018.09.003

[24] Liebowitz SJ AND Margolis SE, 2009, Bundles of joy: the ubiquity and efficiency of bundles in new technology markets, Journal of Competition Law \& Economics, 5(1), pp. 1-47. https://doi.org/10.1093/joclec/nhn013

[25] McAfee RP, McMillan J And Whinston MD, 1989, Multiproduct monopoly, commodity bundling, and correlation of values, The Quarterly Journal of Economics, 104(2), pp. 371-383. https://doi.org/10.2307/2937852

[26] McCardle KF, Rajaram K AND TANG CS, 2007, Bundling retail products: models and analysis, European Journal of Operational Research, 177(2), pp. 1197-1217. https://doi.org/10.1016/j.ejor.2005.11.009

[27] Mialon SH, 2014, Product bundling and incentives for mergers and strategic alliances, Economic Inquiry, 52(2), pp. 562-575. https://doi.org/10.1111/ecin.12047

[28] Parker GG And VAn Alstyne MW, 2005, Two-sided network effects: a theory of information product design, Management Science, 51(10), pp. 1494-1504. https://doi.org/10.1287/mnsc. 1050.0400

[29] Schmalensee R, 1984, Gaussian demand and commodity bundling, The Journal of Business, 57(1), pp. 211-230. http://www.jstor.org/stable/2352937

[30] Shapiro C And Varian HR, 1999, Information rules: a strategic guide to the network economy, Harvard Business Press, Boston.

[31] Stigler GJ, 1973, General economic conditions and national elections, The American Economic Review, 63(2), pp. 160-167. http://www.jstor.org/stable/1817068

[32] Whinston MD, 1990, Tying, foreclosure, and exclusion, American Economic Review, 80(4), pp. 837-859. https://ideas.repec.org/a/aea/aecrev/v80y1990i4p837-59.html

[33] YANG B AND NG CT, 2010, Pricing problem in wireless telecommunication product and service bundling, European Journal of Operational Research, 207(1), pp. 473-480. https://doi.org/10.1016/j.ejor.2010.04.004

[34] Zhоu J, 2017, Competitive bundling, Econometrica, 85, pp. 145-172. 